\title{
KNOWLEDGE REGARDING PREVENTION OF VENTILATOR ASSOCIATED PNEUMONIA AMONG NURSES IN A TERTIARY HOSPITAL, RUPANDEHI, NEPAL
}

Sulochana Ghimire ${ }^{1}$, Srijana Neupane ${ }^{2}$

\begin{abstract}
\section{INTRODUCTION}

Ventilator-associated pneumonia (VAP) is the most frequent and severe infection acquired in the intensive care unit, leading to prolonged mechanical ventilation and excess mortality. This study has been conducted to find out the knowledge regarding prevention of Ventilator Associated Pneumonia (VAP) among nurses.
\end{abstract}

\section{MATERIAL AND METHODS}

A descriptive cross-sectional study was conducted to find out the knowledge regarding prevention of VAP among nurses. Fifty one respondents working in different intensive care areas (ICU, CCU, NICU and PICU) of Universal College of Medical Sciences - Teaching Hospital were selected as the study sample by using census method. Self-administered structured questionnaire was used to collect the data and collected data were analyzed by using descriptive and inferential statistics with SPSS software version 16.

\section{RESULTS}

The findings of the study revealed that $41.2 \%$ and $86.2 \%$ of the respondents had knowledge regarding meaning and causative agent of VAP respectively. The mean percentage of risk factors of VAP and VAP bundle were 86.2 and 61.3 respectively. About $37 \%$ of the respondents had knowledge regarding oral care with chlorhexidine, $86.3 \%$ had knowledge that ventilator circuit should be changed for every new patient and $39.2 \%$ of the respondents had knowledge that closed suction system prevents VAP. The findings of the study revealed that $49.1 \%$ of the respondents had high knowledge and $7.8 \%$ had average knowledge. There was no statistically significant association between respondents' level of knowledge regarding prevention of VAP with respondents' working experience $(p=0.493)$ and qualification $(p=0.459)$.

\section{CONCLUSION}

Based on the study findings, it is concluded that almost half of the respondents have high knowledge regarding prevention of VAP. Besides this, respondents have high knowledge regarding VAP (meaning, causative agent, risk factors, principles and complications) and VAP prevention by positioning, airway humidification and suctioning and low knowledge is found on component of VAP bundle, oral care to reduce VAP and ideal cuff pressure of endotracheal tube.

KEYWORDS Knowledge, nurses, prevention of VAP

1. Lecturer, Universal College of Nursing Sciences, Bhairahawa, Nepal

2. Nursing Officer, Koshi Zonal Hospital, Biratnagar, Nepal

\author{
For Correspondence \\ Ms. Sulochana Ghimire \\ Lecturer, \\ Universal College of Nursing Sciences \\ Bhairahawa, Nepal \\ Email: sanguinegal12@gmail.com
}




\section{INTRODUCTION}

Ventilator associated pneumonia (VAP) is defined as a type of pneumonia in a patient receiving mechanical ventilation that was not present at the time of admission to hospital or that occurs 48 hours after intubation and mechanical ventilation ${ }^{1}$. VAP is the second most common nosocomial infection in intensive care units (ICUs) and the most common in mechanically ventilated patients. Nearly half of all cases of VAP develop within the first 4 days of mechanical ventilation. The risk of VAP is highest early in the course of hospital stay. The risk is estimated to be $3 \%$ per day during the first 5 days of ventilation, $2 \%$ per day during 5-10 days of ventilation and $1 \%$ per day after this ${ }^{2}$. Despite major advances in techniques in caring for patients whose respiratory tracts are instrumented and the routine use of efficient disinfection procedures for the respiratory equipment, VAP continues to complicate the course of 7 to $41 \%$ of patients receiving continuous mechanical ventilation. VAP requires rapid diagnosis and initiation of the appropriate antibiotic treatment, since studies have shown that the delayed administration of appropriate antibiotic therapy in patients with VAP has been associated with excess hospital mortality. VAP rates ranged from 4-14 per 1000 ventilator days in United States and 10-52.7 per 1000 days in developing countries ${ }^{3}$. The National Database of Nursing Quality Indicators (NDNQI) is a national nursing database that provides quarterly and annual reporting of structure, process, and outcome indicators to evaluate nursing care. The NDNQI recognizes VAP as one of the indicators of nursing care. Implementing a guideline that supports evidence-based medicine to decrease VAP rates is consistent with the nurse's role as major health care provider ${ }^{4}$. Nursing care is growing rapidly in conjunction with technology and it is catching up with developed countries guidelines and standards of care. The intensive care nurses need to constantly update themselves with current knowledge and scientific evidence on many issues existent in the ICU, including VAP. Little is known regarding intensive care nurses' knowledge about ventilator care bundle and its application during the provision of patient care. Therefore it is important to evaluate intensive care nurses' knowledge on prevention of VAP ${ }^{5}$. Thus the study has been conducted to find out the knowledge regarding prevention of VAP among nurses.

\section{MATERIAL AND METHODS}

A descriptive cross-sectional study design was used to find out the knowledge regarding prevention of VAP among nurses. Fifty one respondents working in different intensive care areas (ICU, CCU, NICU and PICU) of Universal College of Medical Sciences - Teaching Hospital were selected as a sample for the study by using census method. The main objective was to find out the level of knowledge regarding prevention of VAP among nurses and to find out the association between level of knowledge regarding prevention of VAP and selected demographic variable.

Researcher herself developed self-administered structured questionnaire by seeking literatures, consulting advisor and subject experts. The questionnaire consisted of two parts; Part I - related to socio-demographic variables and Part II - related to knowledge regarding prevention of VAP. Nurses not willing to participate and auxiliary nurse midwives working in intensive care units were excluded from the study.

The study was conducted from $12^{\text {th }}$ February 2017 to $25^{\text {th }}$ April 2017. Pretest of the instrument was conducted on 6 respondents in Devdaha Medical College, Teaching Hospital, Devdaha-9, Bhaluhi, Rupandehi. All the collected data were analyzed by using descriptive statistics and inferential statistics with Statistical Package for Social Sciences (SPSS) software version 16 .

\section{RESULTS}

Socio demographic information included professional qualification, working experience and ICU training as shown in table 1.

Table 1. Respondents' socio-demographic information

\begin{tabular}{|l|c|c|}
\hline Variables & Frequency $(\mathbf{n}=\mathbf{5 1})$ & $\mathbf{\%}$ \\
\hline Professional qualification & & \\
PCL Nursing & 46 & 90.2 \\
$\quad$ Bachelor in Nursing & 5 & 9.8 \\
Working experience & & \\
$\quad$ Less than 12 months & 19 & 37.2 \\
12-24 months & 18 & 35.3 \\
$\quad$ More than 24 months & 14 & 27.5 \\
ICU training & 2 & \\
Received & 49 & 96.1 \\
$\quad$ Not received & \\
\hline
\end{tabular}

Among 51 respondents, $41.2 \%$ answered pneumonia occurring in patients after 48 hours of mechanical ventilation as the meaning of VAP and $5.9 \%$ answered pneumonia occurring in patients after 12 hours of mechanical ventilation as the meaning of VAP. Regarding causative agent of VAP, $86.2 \%$ of the respondents answered Staphylococcus aureus and $2 \%$ of the respondents answered Lactobacillus acidophilus causes VAP. Regarding risk factors of VAP, $82.4 \%$ of the respondents answered underlying heart or lung diseases as the risk factor of VAP and 5.9\% answered obesity as the risk factor of VAP. Knowledge of respondents regarding principles of VAP prevention is shown in table 2. 
Table 2. Respondents' knowledge regarding principles of VAP prevention

\begin{tabular}{l|l|l|}
\hline Principles of VAP prevention** & Frequency $(\mathbf{n}=\mathbf{5 1})$ & Percentage \\
\hline Staff education* & 44 & 86.3 \\
Late weaning & 2 & 3.9 \\
Colonization reduction* & 22 & 43.1 \\
Aspiration avoidance* & 46 & 90.2 \\
Weekly sedation vacation & 4 & 7.8 \\
Implementation of VAP bundle* & 13 & 25.5 \\
**Multiple responses \\
$\begin{array}{l}\text { Mean percentage score- } 61.3 \\
\text { MCorrect response }\end{array}$
\end{tabular}

Majority of the respondents (84.3\%) answered ARDS prevention as a component of VAP bundle and $2 \%$ answered peptic ulcer prophylaxis and deep vein thrombosis prophylaxis as component of VAP bundle. Regarding recommended position to prevent VAP, $41.2 \%$ answered semi-recumbent position as recommended position for ventilated patients to prevent VAP and $11.8 \%$ answered prone position as recommended position for ventilated patients to prevent VAP. Knowledge regarding oral care to prevent VAP is shown in table 3.

Table 3. Respondents' knowledge regarding Oral Care to Prevent VAP

\begin{tabular}{|l|l|l|}
\hline Variables & Frequency (n=51) & Percentage \\
\hline Frequency of oral care for ventilated patients & & \\
Every 1-3 hours & & \\
Every 4-6 hours* & 6 & 11.8 \\
Every 7-9 hours & 6 & 11.8 \\
Above 9 hours & 22 & 43.1 \\
Recommended solution for oral care & 17 & 33.3 \\
Plain water & & \\
Normal saline & 4 & 7.8 \\
Povidone-iodine solution & 23 & 45.1 \\
Chlorhexidine* & 5 & 9.8 \\
& 19 & 37.3 \\
\hline
\end{tabular}

*Correct response

Among 51 respondents, 86.3\% answered ventilator circuit should be changed for every new patient to prevent VAP and $5.9 \%$ answered ventilator circuit should be changed at each shift to prevent VAP. Regarding frequency of changing humidifier, $47.1 \%$ of the respondents answered humidifier should be changed every day to prevent VAP and $7.8 \%$ of the respondents answered humidifier should be changed every week to prevent VAP. Regarding recommended type of humidifier, $66.6 \%$ of the respondents answered heat and moisture exchanger humidifier as recommended type of humidifier to prevent VAP and $2 \%$ of the respondents answered ultrasonic humidifier as recommended type of humidifier to prevent VAP. Results of knowledge regarding suctioning to prevent VAP are shown in table 4
Table 4. Respondents' knowledge regarding suctioning to prevent VAP

\begin{tabular}{|l|l|l|}
\hline Variables & Frequency $(\mathbf{n}=51)$ & Percentage \\
\hline Recommended suction system & & \\
Open suction system & 16 & 31.4 \\
Closed suction system* & 15 & 29.4 \\
Partially open suction system & 13 & 25.5 \\
Partially closed suction system & 7 & 13.7 \\
Frequency of changing suction system & & \\
Each shift & 12 & 23.5 \\
Every day & 16 & 31.4 \\
Every week & 3 & 5.9 \\
For every new patient* & 20 & 39.2 \\
Frequency of suctioning & & \\
Once a day & 1 & 2 \\
Twice a day & 1 & 2 \\
In each shift & 8 & 15.7 \\
When secretions are present* & 41 & 80.3 \\
\hline
\end{tabular}

*Correct response

Regarding suctioning technique that lessens VAP, 45.1\% of the respondents answered oral suctioning lessens VAP and $2 \%$ answered nasal suctioning lessens VAP. Regarding disposal of suction catheter in open suction system, $52.9 \%$ of the respondents answered suction catheter should be disposed after single use in open suction system and $5.9 \%$ of the respondents answered suction catheter should be disposed after using for 2 times in open suction system

Regarding recommended route for endotracheal intubation $58.8 \%$ answered oral route as recommended route for endotracheal intubation and $2 \%$ answered the route for endotracheal intubation depends upon hospital protocol. Regarding tube that decreases bacterial colonization, 33.3\% of the respondents answered double lumen endotracheal tube and silver coated endotracheal tube decreases bacterial colonization and $15.7 \%$ of the respondents answered tracheostomy tube decreases bacterial colonization. Regarding ideal cuff pressure of endotracheal tube, $39.2 \%$ of the respondents answered $20-30 \mathrm{~cm} \mathrm{H}_{2} \mathrm{O}$ as ideal cuff pressure of endotracheal tube and $9.8 \%$ of the respondents answered above $40 \mathrm{~cm} \mathrm{H}_{2} \mathrm{O}$ as ideal cuff pressure of endotracheal tube. Majority of the respondents (92.2\%) answered respiratory failure as complication of VAP and 5.9\% answered hemorrhagic shock as complication of VAP. Table 5 shows the respondents' overall knowledge regarding prevention of VAP

Table 5. Respondents' overall knowledge regarding prevention of VAP

\begin{tabular}{|c|l|l|}
\hline Level of knowledge & Frequency $(\mathrm{n}=\mathbf{5 1})$ & Percentage \\
\hline High & 25 & 49.1 \\
Average & 4 & 7.8 \\
Low & 22 & 43.1 \\
\hline
\end{tabular}

Mean score- 11.75 
Table 6 shows that there was no statistically significant association between respondents' level of knowledge regarding prevention of VAP with respondents' working experience $(\mathrm{p}=0.493)$ and qualification $(\mathrm{p}=0.459)$.

Table 6. Association of resondents' level of knowledge regarding prevention of VAP with respondents' working experience and qualification

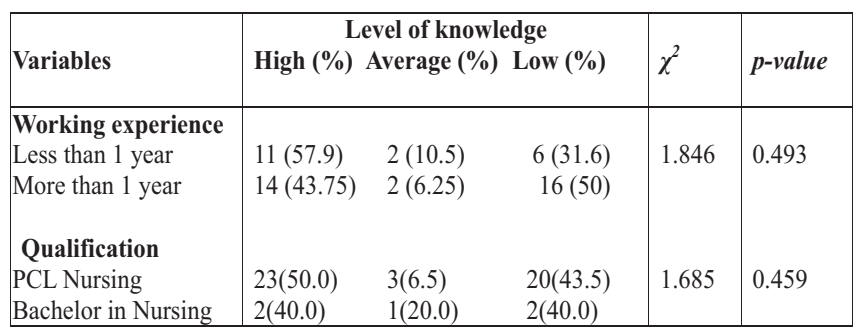

Significance level at 0.05

p-value computed by using Fischer's Exact Test

\section{DISCUSSION}

The findings of the present study showed that $41.2 \%$ of the respondents had knowledge regarding meaning of VAP as pneumonia occurring in patient after 48 hours of mechanical ventilation. The finding is inconsistent with the study ${ }^{6}$ which shows that $70.2 \%$ had knowledge regarding meaning of VAP as pneumonia occurring in patient after 48 hours of mechanical ventilation. The reason of this difference might be due to the fact that in the study ${ }^{6} 94.7 \%$ of nurses had a bachelor's degree and in the present only $9.8 \%$ had completed Bachelor Nursing.

The findings of the present study showed that $41.2 \%$ of the respondents had knowledge regarding semi-recumbent position as recommended position for ventilated patients to prevent VAP. The finding is consistent with the study ${ }^{7}$ which shows that $42.7 \%$ had knowledge regarding semi-recumbent position as recommended position for ventilated patients to prevent VAP. Again, the findings of the study showed that $52.9 \%$ of the respondents had knowledge regarding disposal of suction catheter after single use in open suction system. The finding is consistent with the study ${ }^{7}$ which shows that $50.4 \%$ had knowledge regarding disposal of suction catheter after single use in open suction system.

The findings of the present study showed that $29.4 \%$ of the respondents had knowledge regarding closed suction system as recommended type of suction system to prevent VAP. The finding is inconsistent with the study ${ }^{8}$ which shows that $55.4 \%$ had knowledge regarding closed suction system as recommended type of suction system to prevent VAP. Likewise the study ${ }^{9}$ showed $87 \%$ had knowledge that suction system should be changed for every new patient to prevent VAP and findings of the present study showed that $39.2 \%$ of the respondents had knowledge that suction system should be changed for every new patient to prevent VAP. The difference in these findings might be due to the difference between working experience of the respondents. In the study ${ }^{8} 85.2 \%$ and in the study $90.2 \%$ of the respondents had working experience of more than 1 year while in the present study $62.8 \%$ of the respondents has working experience of more than 1 year. The findings of the study showed that $37.3 \%$ of the respondents had knowledge regarding chlorhexidine as recommended solution for oral care to prevent VAP. The finding is inconsistent with the study ${ }^{10}$ which shows that $82.9 \%$ had knowledge regarding chlorhexidine as recommended solution for oral care to prevent VAP. In the study ${ }^{10}$ nurses working in ICUs who do not provide care for critically ill patients on mechanical ventilation were excluded but in the present study all the nurses working in critical care unit were included without considering whether they provide care for critically ill patients on mechanical ventilation or not. Data from a study ${ }^{11}$ indicated that $67.1 \%$ of the respondents had knowledge that subglottic suctioning technique lessens VAP. This differs from the present study which showed that $11.7 \%$ of the respondents had knowledge that subglottic suctioning technique lessens VAP. This difference in the findings might be due to that in the study ${ }^{11} 82.93 \%$ of the respondents had received ICU training and in the present study only $3.9 \%$ has received ICU training.

The findings of the present study showed that $7.8 \%$ of the respondents answered humidifier should be changed every week to prevent VAP. The finding is consistent with the study $^{12}$ which shows that $3.8 \%$ had knowledge regarding humidifier should be changed every week to prevent VAP.

\section{CONCLUSION}

On the basis of the findings of the study, it is concluded that almost half of the respondents have high knowledge regarding prevention of VAP. Besides this, respondents have high knowledge regarding VAP (meaning, causative agent, risk factors, principles and complications) and VAP prevention by positioning, airway humidification and suctioning and low knowledge is found on component of VAP bundle, oral care to reduce VAP and ideal cuff pressure of endotracheal tube. There was no statistically significant association between working experience and respondents' level of knowledge regarding prevention of VAP. Furthermore, looking at the findings it can be concluded that specialized / formal education on critical care nursing and training would help to improve knowledge of nurses which ultimately will aid on quality of nursing care. 


\section{REFERENCES}

1. Said AT. Knowledge and practice of intensive care nurses on prevention of ventilator associated pneumonia at Muhimbili national hospital, Dar es Salaam, Tanzania (Doctoral dissertation, Muhimbili University of Health and Allied Sciences; 2012)

2. Gadani H, Vyas A, Kar AK. A study of ventilator-associated pneumonia: Incidence, outcome, risk factors and measures to be taken for prevention. Indian journal of anaesthesia. 2010 Nov; 54(6):535-543.

3. Ranjan N, Chaudhary U, Chaudhry D, Ranjan KP. Ventilatorassociated pneumonia in a tertiary care intensive care unit: Analysis of incidence, risk factors and mortality. Indian journal of critical care medicine: peer-reviewed, official publication of Indian Society of Critical Care Medicine. 2014 Apr;18(4):200207.

4. Gallagher JA. Implementation of ventilator-associated pneumonia clinical guideline (Bundle). The Journal for Nurse Practitioners. 2012 May 31;8(5):377-382.

5. Sebastian AM. A study to assess the knowledge of cardiac nurses about ventilator care bundle in congenital cardicac ICU in Sree Chitra Tirunal Institute for Medical Science and Technology (Doctoral dissertation; 2011).

6. Yeganeh M, Yekta H, Farmanbar R, Khalili M. Knowledge of evidence-based guidelines in Ventilator-Associated Pneumonia prevention. Journal of evidence-based medicine. 2016 Jan 1;4 (1) $: 1-2$
7. Aferu, B. Assessment of knowledge and practice of nurses working in the ICU towards prevention of ventilator associated pneumonia at selected governmental hospitals, Addis Ababa, Ethiopia (Masters dissertation; 2016).

8. Jansson M, Ala-Kokko T, Ylipalosaari P, Syrjälä H, Kyngäs H. Critical care nurses' knowledge of, adherence to and barriers towards evidence-based guidelines for the prevention of ventilator-associated pneumonia. 2013 August 29(4):216-227.

9. El-Khatib MF, Zeineldine S, Ayoub C, Husari A, Bou-Khalil PK. Critical care clinicians' knowledge of evidence-based guidelines for preventing ventilator-associated pneumonia. American Journal of Critical Care. 2010 May 1;19(3):272-276.

10. Al-Sayaghi KM. Prevention of ventilator-associated pneumonia. Saudi Med J. 2014 Mar 1;35(3):269-276.

11. Malombe PM. Evaluation of nurses'knowledge and prevention practices of ventilator associated morbidities in critical care unit, Kenyatta National hospital (doctoral dissertation, University of Nairobi; 2015).

12. Bagheri-Nesami M, Amiri-Abchuyeh M, Gholipour-Baradari A, Yazdani-Cherati J, Nikkhah A. Assessment of Critical Care Provider's Application of Preventive Measures for VentilatorAssociated Pneumonia in Intensive Care Units. Journal of clinical and diagnostic research: JCDR. 2015 Aug;9(8):IC0508 . 